\title{
Perception of University Female Students on Factors Affecting Their Academic Performance and Competency: A Study from Dire Dawa University, Ethiopia
}

\author{
Hailemariam Mamo, Getiye Gosa, Beza Hailu \\ Department of Biological Sciences, Dire Dawa University, Dire Dawa, Ethiopia
}

Email address:

hailemariammamo5@gmail.com (H. Mamo)

\section{To cite this article:}

Hailemariam Mamo, Getiye Gosa' Beza Hailu. Perception of University Female Students on Factors Affecting Their Academic Performance and Competency: A Study from Dire Dawa University, Ethiopia. Science Journal of Education. Vol. 5, No. 5, 2017, pp. $211-215$. doi: 10.11648/j.sjedu.20170505.15

Received: December 20, 2016; Accepted: December 28, 2016; Published: October 3, 2017

\begin{abstract}
Although, improvement has been observed in Ethiopia, female students' academic competency and performance is low compared with male students because of various economical, environmental or socio cultural factors resulting higher attrition rate in their academic success. The study was designed to assess female students' perception on factors affecting their academic competency and performance. Cross-sectional study and random sampling was applied among Dire Dawa University senior female students. Questionnaire and structured interview were used for data collection. Female students' perception on various factors was addressed. Most female students agreed that institutional, family and their background, environmental and socio-cultural, behavioral and commitment related factors affect their academic performance and competency. They perceived that lack of self-confidence, stress, lack of preparation, university related factors (lack of proper reading place, lack of proper guidance), and students and teachers characteristics influence their competency and performance. The university management, parents, students themselves and other concerned bodies should work to reduce factors that affect academic performance and competency of female students. Projects should be designed to alleviate the problems so as to make female students competent and successful in their academic life.
\end{abstract}

Keywords: Female Students Perception, Academic Performance, Competency

\section{Introduction}

The number and proportion of female students is lower in Ethiopian higher educational institutions compared to male students [1]. To address this gap the government has formulated and has been implementing various strategies to increase females' participation in education, decision making and developmental activities. As a result, their participation is improving and appreciable through years. However, female students' participation decline along grade levels mainly in colleges and universities. Females who graduate from higher learning institutions and their graduation rate is lower compared to male graduates $[2,3]$.

Education is harmonious development and vital for every wise human activity [3]. It is linked with individual's wellbeing and opportunities for better living and enables citizens to make all rounded participation [3,4]. But, its quality, relevancy and students competency can be affected by different factors [3]. Academic performance and competency are one of the indicators for educational quality which are measured in terms of students' achievement and capability towards specific objectives of courses or academic programs.

Factors affecting students' academic performance and competency are related to students' background, family related, university, environment and socio cultural settings, behavioral and commitment [2, 5-8]. In Ethiopian context, these factors mostly influence female students for various reasons. Factors within and off the university and facilities related problems such as academic and administrative rules, peer pressure, lack of female role model teachers, lack of different supportive trainings and tutorial classes are the major ones among others [2].

Perception is understood as the positions, attitudes, affects and behaviors that an individual exhibits towards certain 
processes, situations, objects or persons [9, 10], Students' perception and attitudes towards their academic training and associated factors is useful to address challenges and improving learning situations to develop appropriate instructional approaches. Thus, this study was designed to explore female students' perceptions on factors affecting their academic performance and competency for institutional intervention.

\section{Methodology}

The study was conducted on female students' perception on factors affecting their academic competency and performance in case of Dire Dawa University, Ethiopia. Cross sectional study was used by using questionnaires. Totally, 135 students proportional to each academic unit were participated. Seven students abstained at middle of data collection. Respondents were provided with selfadministered questionnaire and interviewed. Questionnaire was developed based on six point Likert scale format to address their level of agreement and perception towards anticipated factors affecting their academic competency and performance. For reliability of the instrument, a pilot study was conducted. The data obtained through the pilot study were analyzed. The questionnaire was revised and was administered on the actual sample of the study for data collection. Demographic characteristics, factors related with background, institutional, environmental, socio-cultural and students' behavior and commitment were addressed.

\section{Result}

In Ethiopia, participation of female students is increasing at all education levels. But female students who graduate from higher learning institution are still less as compared with male graduates. This is because of various reasons. Their perception and awareness on these factors is important and female students can be part of the solution. This study has focused on university female students' perception on factors affecting their academic performance and competency among senior Dire Dawa University female students implication for intervention. Family and background related factors, college and university related factors, environment and socio cultural related factors, behavioral and commitment related factors were addressed by the students' level of agreement on various factors under the categories.

Table 1. Number and proportion of study participants across colleges.

\begin{tabular}{lll}
\hline & Colleges/Institute & Number (\%)of female participants \\
\hline 1. & College of natural and computational science & $25(19.5 \%)$ \\
2. & College of medicine and health Sciences & $9(7.0 \%)$ \\
3. & Institution of technology & $56(43.8 \%)$ \\
4. & College of social science and Humanity & $12(9.4 \%)$ \\
5. & College of Law & $6(4.7 \%)$ \\
6. & College of Economics and Business & $21(16.4 \%)$ \\
& Total & $128(100 \%)$ \\
\hline
\end{tabular}

Table 2. Female students perception on family and students background related factors.

\begin{tabular}{|c|c|c|c|c|c|c|}
\hline \multirow{2}{*}{ Family and students Backgroundrelated Factors } & \multicolumn{6}{|c|}{ Level of agreement (Number (\%)) } \\
\hline & Always true & Usually true & Sometimes true & Neutral & Rarely true & Never true \\
\hline 1. Poor academic backgroundand low prior knowledge & $42(32.81)$ & $42(32.81)$ & $27(21.1)$ & $4(3.13)$ & $6(4.69)$ & $7(5.47)$ \\
\hline 2. Poor in English Language and basic subjects & $42(32.81)$ & $39(30.47)$ & $23(17.96)$ & $12(9.70)$ & $4(3.12)$ & $8(6.25)$ \\
\hline 3. Family concerns for those are already married. & $21(16.41)$ & $33(25.28)$ & $36(26.13)$ & $18(14.06)$ & $11(8.59)$ & $9(7.03)$ \\
\hline 4. Parents' education level. & $34(26.56)$ & $31(24.22)$ & $24(18.75)$ & $21(16.41)$ & $12(9.38)$ & $6(4.63)$ \\
\hline 5. Economic status of parents, & $46(35.94)$ & $23(17.96)$ & $31(24.22)$ & $12(9.38)$ & $11(8.59)$ & $5(3.91)$ \\
\hline 6. Limitedparental involvement in academic activities & $25(19.53)$ & $47(36.72)$ & $34(26.56)$ & $10(7.81)$ & $7(5.47)$ & $5(3.91)$ \\
\hline
\end{tabular}

Table 3. Response of participants on college/university related factors.

\begin{tabular}{|c|c|c|c|c|c|c|}
\hline \multirow{2}{*}{ Backgroundand Family related Factors } & \multicolumn{6}{|c|}{ Level of agreement (Number (\%)) } \\
\hline & Always true & Usually true & Sometimes true & Neutral & Rarely true & Never \\
\hline 1. Inadequate facilities (books, references etc.) & $34(26.56)$ & $35(27.34)$ & $36(28.13)$ & $10(7.81)$ & $5(3.91)$ & $8(6.25)$ \\
\hline 2. Inappropriate learning environment. & $39(30.47)$ & $32(25)$ & $34(26.56)$ & $12(9.38)$ & $9(7.03)$ & $2(1.56)$ \\
\hline 3. Insufficient instruction (amount and quality) & $26(20.31)$ & $47(36.72)$ & $24(18.75)$ & $18(14.06)$ & $8(6.25)$ & $5(3.91)$ \\
\hline 4. Inappropriate dormitory, classroom, café and facilities. & $46(35.94)$ & $33(25.78)$ & $32(25)$ & $8(6.25)$ & $5(3.91)$ & $4(3.13)$ \\
\hline 5. Types of Course or field they study & $36(28.13)$ & $41(32.03)$ & $26(20.31)$ & $18(14.06)$ & $4(3.13)$ & $3(2.34)$ \\
\hline 6. Poor campus and curriculum nature for competency & $26(20.31)$ & $23(17.97)$ & $40(31.25)$ & $20(5.63)$ & $11(8.59)$ & $8(6.25)$ \\
\hline 8. Teachers quip quo pro (instructors bias and harassment) & $37(28.91)$ & $32(25)$ & $26(20.31)$ & $17(13.28)$ & $12(9.38)$ & $4(3.13)$ \\
\hline 9. Lack of special support by the university & $23(17.97)$ & $33(25.78)$ & $29(22.66)$ & $16(12.5)$ & $17(13.28)$ & $10(7.81)$ \\
\hline 10. Poor Assessment and examination approach & $40(31.25)$ & $47(36.71)$ & $29(22.66)$ & $5(3.91 \mid)$ & $4(3.13)$ & $3(2.34)$ \\
\hline 11. Academic and administrative rules and regulations & $23(17.99)$ & $34(26.56)$ & $47(36.71)$ & $5(3.91)$ & $10(7.82)$ & $9(7.03)$ \\
\hline 12. Lack of female role model teachers & $37(28.91)$ & $32(25)$ & $26(20.31)$ & $18(14.06)$ & $9(7.03)$ & $8(6.25)$ \\
\hline 13. Lack of different supportive trainings & $25(19.53)$ & $28(21.88)$ & $28(21.88)$ & $23(17.97)$ & $14(10.94)$ & $10(7.81)$ \\
\hline 14. Department choice of students. & $55(42.97)$ & $29(22.66)$ & $23(17.97)$ & $10(7.81)$ & $8(6.25)$ & $3(2.34)$ \\
\hline
\end{tabular}


Table 4. Participants response on environment and socio-culture related factors.

\begin{tabular}{|c|c|c|c|c|c|c|}
\hline \multirow{2}{*}{ Environment and Socio-Culture related factors } & \multicolumn{6}{|c|}{ Level of agreement (Number (\%)) } \\
\hline & Always true & Usually true & Sometime true & Neutral & Rarely true & Never true \\
\hline 1. Low geographical belongingness and longing. & $18(14.06)$ & $34(26.56)$ & $40(31.25)$ & $18(14.06)$ & $8(6.25)$ & $10(7.81)$ \\
\hline 2. Night club/bars, around the university & $43(33.59)$ & $35(27.34)$ & $29(22.66)$ & $11(8.59$ & $5(3.91)$ & $5(3.59)$ \\
\hline 3. Limited job opportunities so that low interest to education & $48(37.5)$ & $31(24.23)$ & $24(18.75)$ & $8(6.25$ & $11(8.59)$ & $6(4.69)$ \\
\hline 4. The off-campus factors like culture and traditions & $17(13.28)$ & $29(22.66)$ & $35(27.34)$ & $20(15.63$ & $16(12.5)$ & $11(8.59)$ \\
\hline 5. Challenging and discomforting weatherand climate & $46(35.94)$ & $36(28.13)$ & $26(20.31)$ & $10(7.81$ & $5(3.91)$ & $5(3.91)$ \\
\hline
\end{tabular}

Table 5. Participants response Student behavior and commitment related factors.

\begin{tabular}{|c|c|c|c|c|c|c|}
\hline \multirow{2}{*}{ Studentsbehavior and commitment related factors } & \multicolumn{6}{|c|}{ Level of agreement (Number (\%)) } \\
\hline & Always true & Usually true & Sometime true & Neutral & Rarely true & Never true \\
\hline 1. Missing class attendance & $45(35.16)$ & $32(25)$ & $32(25)$ & $7(5.47)$ & $3(2.34)$ & $9(7.03)$ \\
\hline 2. Poor studying habit and poor time management & $50(39.06)$ & $40(31.25)$ & $21(16.41)$ & $3(2.34)$ & $5(3.91)$ & $9(7.03)$ \\
\hline 4. Aptitude (ability, development and motivation) & $43(33.39)$ & $39(30.47)$ & $24(18.75)$ & $11(8.59)$ & $5(3.61)$ & $6(4.69)$ \\
\hline 5. Religious affiliations giving low emphasis for education & $23(17.99)$ & $30(23.44)$ & $24(18.75)$ & $18(14.06)$ & $9(7.03)$ & $24(18.75)$ \\
\hline 6. Low student's effort and motivation & $24(18.75)$ & $48(37.5)$ & $35(27.34)$ & $8(6.24)$ & $7(5.47)$ & $6(4.69)$ \\
\hline 8. Stress and anxiety frightening failure & $60(46.88)$ & $38(29.69)$ & $20(15.63)$ & $4(3.13)$ & $3(2.34)$ & $3(2.34)$ \\
\hline 9. Students perception towards their academic performance & $27(21.09)$ & $45(35.16)$ & $32(25)$ & $9(7.03)$ & $9(7.03)$ & $6(4.69)$ \\
\hline 10. Substance abuse and risky behaviours & $51(39.84)$ & $24(18.75)$ & $25(19.53)$ & $20(15.63)$ & $5(3.91)$ & $3(2.34)$ \\
\hline 11. Female students living outside and being non café & $48(37.5)$ & $22(17.19)$ & $29(22.66)$ & $10(7.81)$ & $10(7.81)$ & $9(7.03)$ \\
\hline 12. Female students low self esteem/perception & $32(25)$ & $25(19.53)$ & $37(28.91)$ & $20(15.63)$ & $6(4.69)$ & $8(6.25)$ \\
\hline 13. Lowparticipation in extracurricular activities & $15(11.72)$ & $30(23.43)$ & $32(25)$ & $30(23.44)$ & $11(8.59)$ & $10(7.81)$ \\
\hline 14. Low frequency to visit instructors for advise per week & $18(14.06)$ & $35(27.34)$ & $34(26.56)$ & $15(11.72)$ & $15(11.72)$ & $11(8.59)$ \\
\hline
\end{tabular}

\section{Discussion}

The main challenge of higher education institutions in Ethiopia is to develop professionals capable of understanding and responding to the current social priorities of the country. Educational quality and equity is not yet attained. In Ethiopia, participation of female students is increasing at all education levels [1]. But, female students who graduate from higher learning institutions are still less as compared with male graduates $[2,3,5]$. Significant numbers of female students has been still academically dismissed from the universities though attrition rate though varies from colleges to colleges even from departments to departments. High failure rates are costly to all levels since increases the cost of training graduates as well as reducing admission opportunities for high school students seeking a higher education [11].

These failures are because of various reasons. Students' motivation and individual characteristics, social, economic, cultural, and community characteristics, family background, institutional characteristics, gender and other demographic factors affect academic performance and competency [7]. Female students have faced different challenges from elementary to higher education level. In fact, factors that affect females also affect male students. However, factors related to family and background, college and university related factors, environmental and socio cultural factors greatly affect females' academic performance and competency $[9,10]$.

\section{Family and students Background related factors}

Academic background is one of the major factors for their low academic performance [2,5]. Prior knowledge in English language and other basic subjects is very important for college success. In most cases, female students' participation and assessment results indicate those with poor academic background are low achievers. Most study participants agree that it is true such academic background related factors affect students' performance at college and university level (table 2).

Family educational status, follow up and support were other factors taken in to consideration. Most respondents agreed that family and related factors influence their performance and competency. Family economic status affects female students' academic performance. Low socioeconomic status has negative effect on academic performance of students because the basic needs of students remain unfulfilled and hence they do not perform better [4]. Female students suffer difficulty of buying cosmetics and hygienic materials. As a result they may engage in different and risky activities such as sexual and other risky behaviors for such gain. Such involvement hinders them from academic activities and active participation. Related studies showed that students from illiterate and poor family will face very limitation to purchase necessary educational materials and hard to fulfill their necessary demands [4]. Female students from family of poor economic background may have low self esteem feeling inferior. The study implied that parental support and involvement and locus of control in all areas have significant effect on students' academic achievement. Educated parents better closely follow and support their daughters motivate them to score better academically. However, it is not always true because a number of female students from less educated and economically poor score higher results and sometimes become medalist all along departments and colleges. 


\section{College and University related factors}

Perceived College/University related factors are connected with facilities like its inadequacy and inappropriateness. Some studies indicated that university related factors such as lack of facilities, university rules and regulations, department choice of students and lack special support affect their academic performance [3, 4]. For example, inadequate and discomfort able dormitory and classrooms, shortage of learning materials like books, internet access and cafeteria are among others. Others factors related with curriculum, syllabus, teaching learning, and management as well as administrative related. The present study showed that factors within the university have been affecting the female students' academic performance and competency (table 3). Most respondents $(82.02 \%)$ agreed that shortage of learning materials like reference books hinder their performance. Quality of dormitory, classrooms, and café services has also impact on their competency. Such factors related with the environment; the desert climate; increase the need to special attention in these facilities. Significant number of participants $(80.03 \%)$ replied that dormitory, classroom and café services related factors require the institution attention. Majority $(86.72 \%)$ of participate female students said that the environment and climate is challenging.

Other institutional related factors considered were curriculum, syllabus, teaching learning and assessment methods. Teachers' quality and behavior as well as management and administrative related factors influence students' academic achievement. Professional development can influence teachers' classroom practices and lead to improved students' achievement when it focuses on how students learn a particular subject matter; instructional practices that are specifically related to the subject-matter and content [9]. These inputs and procedures of higher education should be verified by quality assurance which is checking monitoring and enhancing systems, procedures, processes and intended actions in line with standards [12].

Lack of different special supportive trainings, guidance and counseling services, harassment and insecurity in and off campus were discussed (table 3 ). Most respondents (90.62\%) admitted that poor assessment and evaluation that may not measure students' knowledge, attitude and skills affect their competency. Assessment of student learning is a systematic process of collecting information about student progress towards the learning goals [13]. It should be to assess cognitive development, attitude and students' ability to comprehend, synthesize, analyze, compare, contrast, relate, articulate, write and evaluate. Assessment should be valid and reliable in that instructors genuinely and consistently assess students' performance and competency. They should facilitate the students' participation in the evaluation process. They should emphasize real-world problems, tasks, or applications that are relevant to the student and the community context [13]. Students' department choice with their interest also affects their academic performance $(83.6 \%)$ psychologically and in terms of readiness. Teachers quip quo pro (instructors bias and harassment (74.22\%) and poor student-teacher relationship affect female students academic performance. Teachers' professionalism, planned classroom practice and positive interaction with students have vital importance in learning improvementand enhancing students' academic competency [9].

Environment and socio cultural related factors

Learning environment is determining factors for female students' academic performance [1]. Factors related institution and learning environment associated with students' success (table 4). Women participation in higher education is influenced by various environmental and socio-cultural factors [14]. Learning and teaching environment are related with informing, communicating, collaborating, producing, scaffolding, and managing educational activities. This might be affected by learning environment which is the whole range of components and activities within which learning happens [15]. Most students come from different geographical areas. Dire Dawa is hot and desert city. The Weather and climatic conditions challenge most of the students. Socio cultural factors such as students' interaction one to the other as well as surrounding society for shopping, recreation or in any other concerns could influence positively or negatively. According to their perception weather and climatic condition has great influence on their academic success. About $84.38 \%$ of the respondents agreed such factor forced them to miss classes, to study effectively on day time or night, and lead them for lower interest on their education. Significant number of respondent female students (83.59\%) agreed that night club/bars and drug abuse around the university vicinity exposed them to risky behaviors.

Students' behavior and commitment related factors

Students' undesired behavior affecting education is characterized by missing class attendance, low studying habit and poor time management and lack of attention [16]. Their studying and learning approach play great role in achievement. While there is some diversity in the terms used, there is a fair degree of empirical evidence that students adopt two basic orientations or approaches. A deep approach to learning is described as striving for improved understanding by applying and comparing ideas. Conversely, 'surface' learning involves reproductive strategies with little attempt to integrate information [17]. Such behavioral factors affect female students' academic performance (table 5). About $85.16 \%$ of respondent female students admitted that missing class attendance was problematic. Low self esteem and wrong perception on courses also affected their academic performance (73.44\%). Some considered themselves below males and shoed sense of dependency on special privileges given in the University as Dire Dawa University provides special tutorial and other supports for female students exceptionally. Other problems related to students' behavior includes stress and anxiety as major factor affecting female students' confidence and inspiration to their success. About $92.2 \%$ of respondents agreed that students had lack of self confidence thinking difficulty of some courses. Substance abuse and related 
risky behaviors were reported problems that led some live outside campus and unsafe vicinity that demolish their interest and time to study. Self-learning, readiness, personal orientation and anxiety orientation contribute great for academic competency. It fosters positive attitude and self confidence illustrating own personal abilities through internal orientation [18].

\section{Conclusion}

Female students' academic performance and competency were affected by different factors as stated by themselves. Institutional related factors, family and background related factors, environmental and socio-cultural factors, student's behavior and commitment related factors were major themes of female students' poor academic performance and Competency.

\section{Recommendation}

Problems affecting the female students' academic performance were multiple. Students, families surrounding community, university management and instructors have their shared role in alleviating challenges affecting female students' academic performance. Background related problems like poor English language and computing proficiency, bad habits and low motivation/confidence should be reduced mainly by students using existing opportunities and privileges provided. However, more is expected from the instructors and different university management units to make students competent and confident. Strict follow up for risky behaviors, creating conducive learning facilities, targeted support based on real evidence should be the major actions among others.

\section{References}

[1] MoE; (2014) A study of Gender Gap Enrollment Retention and Performance in Primary School, Addis Ababa,Ethiopia.

[2] Yeshimebrat Mersha, Alemayehu Bishaw and Firew Tegegne (2013). Factors Affecting Female Students' Academic Achievement at Bahir Dar University, Ethiopia, Journal of International Cooperation in Education, Vol.15 No. 3pp. 135148 .

[3] Wudie Atnaf Tiruneh and Philipos Petros (2014). Factors affecting female students' academic performance at higher education: The case of Bahir Dar University, Ethiopia: African Educational Research Journal Vol. 2 (4), pp. 161-166.

[4] M. S. Farooq, A. H. Chaudhry, M. Shafiq, G. Berhanu (2011). Factors Affecting Students' Quality of Academic Performance: A Case Of Secondary School Level Journal of Quality and Technology Management Volume VII, Issue II, Page 01-14.

[5] Kyoshaba Martha (2009). Dissertation Submitted too Graduate School in Partial Fulfillment of the Requirements for the Award of the Degree of Master of Arts in
EducationalManagement of Makerere University: unpublished.

[6] Mojgan Afshari, Kamariah Abu Bakar, (2009). Wong Su Luan, Bahaman Abu Samah \& Foo Say FooiFactors Affecting TeachersUse Of InformationAnd Communication Technology International Journal of Instruction January Vol. 2, No. 1.

[7] M. Mazharul Islam (2014). Factors Influencing the Academic Performance of Undergraduate Students in Sultan Qaboos University in Oman: Journal Of Emerging Trends in Educational Research and Policy Studies (JETERAPS) 5 (4).

[8] Shoukat Ali1, Zubair Haider, Fahad Munir1, Hamid Khan1, Awais Ahmed (2013). Factors Contributing to the Students Academic Performance: A Case Study of Islamia University Sub-Campus American Journal of Educational Research, Vol.1, No. 8, pp 283-289 Available online athttp://pubs.sciepub.com/education/1/8/3.

[9] Ewnetu Hailu andFirdisa Jabessa (2010). Teachers' Perceptions of School Based Continuous Professional Evelopment in Jimma Zone Selected Schools, Ethiop. J. Educ. \& Sc. Vol. 5 No 2.

[10] Víctor Manuel, Mendoza-Núñez, María de la, Luz MartínezMaldonado andElsa Correa-Muñoz (2007). Perceptions on the importance of gerontological education by teachers and students of undergraduate health sciences Published: BMC Medical Education vol.7doi:10.1186/1472-6920-7-1.

[11] Victor Mlambo, (2011), Analysis of Some Factors Affecting Students Academic Performance, in an introductory biochemistry course at the University of the West Indies Caribbean Teaching ScholarVol. 1, No. 2, November 2011, 79-92.

[12] Husain Salilul Akareem and Syed Shahadat Hossain (2016). Determinants of education quality: what makes students' perception different?, Open Review of Educational Research, 3:1, 52-67, DOI: 10.1080/23265507.2016.1155167.

[13] Mussawy, Sayed Ahmad Javid (2009) Assessment Practices: Student's and Teachers' Perceptions of Classroom Assessment Master's Capstone Projects. Paper 9: available on $\mathrm{http}: / /$ scholarworks.umass.edu/cie_capstones.

[14] Jane Onsongo, (2004). Factors Affecting women's Participation in University Management in Kenya, OSSREA, Ethiopia.

[15] Basque, Josianne \& Sylvie Doré. (1998). Le concept d'environnement d'apprentissage informatisé. Journal of Distance Education/Revue de l'enseignement à distance, 13 (1), ISSN 0830-0445.

[16] Tesfaye Wotengo et al (2014). Assessment of Factors Influencing Academic Achievement of Female, Addis Ababa University, Ethiopia.

[17] Marton, F. \& Sa“ Ljo“, R. (1976). Symposium: learning processes and strategies. On qualitative differences in learning: Outcome as a function of the learner's conception of the task, British Journal of Educational Psychology, 46, pp. 115-127.

[18] A. Seda Yucel (2007). Factors Affecting Teaching the Concept of Renewable Energy in Technology Assisted Environments and Designing Processes in the Distance Education Model. Turkish Online Journal of Distance Education, Volume: 8. 